\title{
Failure Analysis of Weld Cracking in External Cold Water Pipeline of Condenser in Converter Station
}

\author{
Jun Wang ${ }^{1, *}$, Yaxia Qiao ${ }^{2}$, Hao Zhang ${ }^{2}$ and Hongjian Lou $^{3}$ \\ ${ }^{1}$ State Grid Hunan Electric Power Company Limited Research Institute, Changsha 410007, China \\ ${ }^{2}$ China Electric Power Research Institute, Beijing,100192, China \\ ${ }^{3}$ State Grid Zhejiang Electric Power Research Institute, Hangzhou, 410007, China
}

\begin{abstract}
The cause of weld cracking in external cold water pipeline of condenser in a $\pm 800 \mathrm{kV}$ converter station were analyzed by macro inspection, chemical composition analysis, hardness test, microstructure inspection, scanning electron microscopy and energy spectrum test methods. The results show that the main reason for the cracks is that the material and manufacturing process are not qualified, and the welding process is not good. Corresponding control measures are put forward to avoid similar failures from happening again.
\end{abstract}

\section{Introduction}

For large-scale active power transmission of UHVDC, it is necessary to match dynamic reactive power with sufficient capacity to compensate ${ }^{[1]}$. At present, it is common to use a condenser to adjust the reactive power, which is also the scope and adjustment method of a dynamic reactive power compensation device. The structure of large-capacity condenser is mainly composed of the condenser body, excitation system, step-up transformer, starting system, cooling system, oil system and control protection system ${ }^{[2,3]}$. The cooling system contains a large number of pipes, and the reliability of its connection is directly related to the operation safety of the entire condenser ${ }^{[4]}$.

In this paper, a failure of a weld in external cold water pipeline of condenser in a $\pm 800 \mathrm{kV}$ converter station was investigated. Through macro inspection, chemical composition analysis, hardness test, microstructure inspection and scanning electron microscope and energy spectrum tests, the causes of weld cracking were analyzed to provide a reference for design and manufacturing, inspection and testing, and operation and maintenance.

\section{Experiment section}

A FOUNDRY-MASTER PRO Oxford full-spectrum direct-reading spectrometer was used to analyze the chemical composition of the welded joint. The schematic diagram of the detection position is shown in Fig. 1. The hardness test is carried out on the HBE-3000A electronic Brinell hardness tester. The schematic diagram of the test position is shown in Fig.2. Observe the microstructure of the welded joint under the Zeiss Axio Observer A1m metallographic microscope. The metallographic samples were observed and analyzed by ZEISS EVO18 scanning electron microscope (SEM).

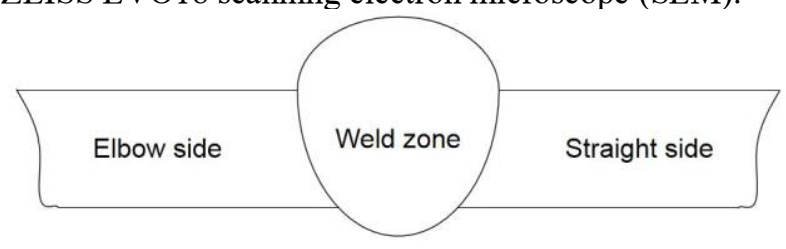

Fig. 1. Component detection position diagram

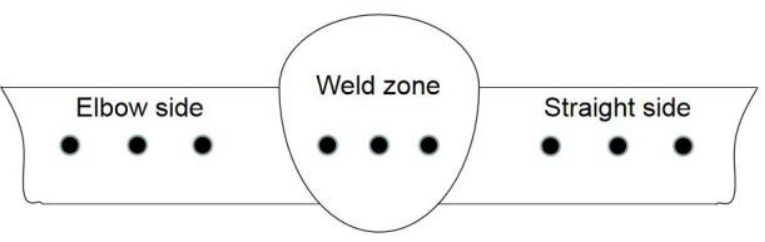

Fig. 2. Schematic diagram of hardness testing position

\section{Results and discussion}

\subsection{Macro inspection}

The leaky elbow weld has obvious signs of repair welding. The width of the weld is $17.7 \mathrm{~mm}$. According to the standard DL/T 869-2012 "Welding Technical Regulations for Thermal Power Plants", the width of the weld should not exceed $12 \mathrm{~mm}$. The appearance quality of the weld is not satisfactory as shown in Fig.3. There are many penetrating cracks on the surface near the side of the bend of the weld, all of which extend longitudinally along the weld, 2 to $4 \mathrm{~mm}$ from the weld toe, and 20 to $50 \mathrm{~mm}$ in length, as displayed in Fig.4. It is founded that The base metal area corroded slightly and the weld area corroded severely by inspecting the inner wall of the elbow, as shown in Fig.5. Contrast check the

\footnotetext{
*Corresponding author: 279091498@qq.com
} 
inner wall of the same type of non-leakage elbow, it can be seen that the weld zone is more corrosive than the base metal zone, and the groove is not opened before welding as displayed in Fig.6.

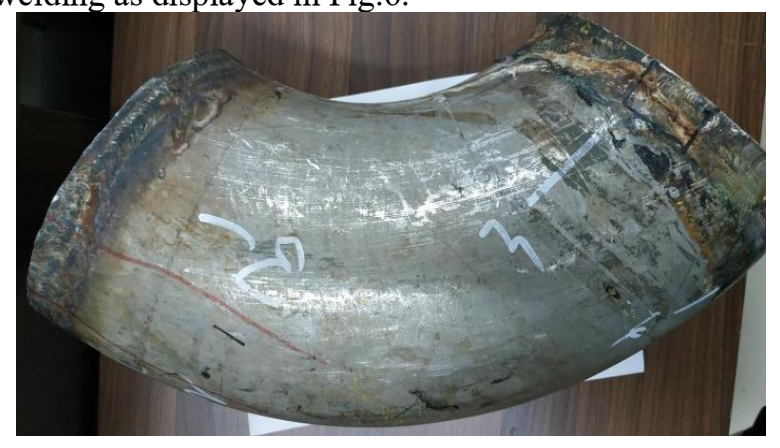

Fig. 3. The appearance of Elbow weld

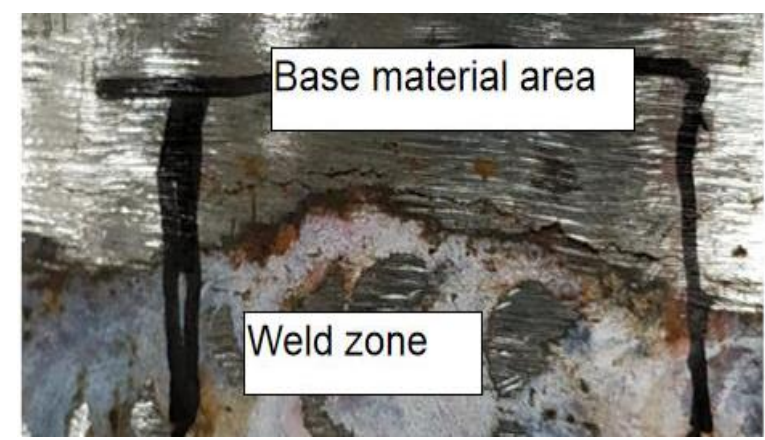

Fig. 4. Cracks in the weld zone

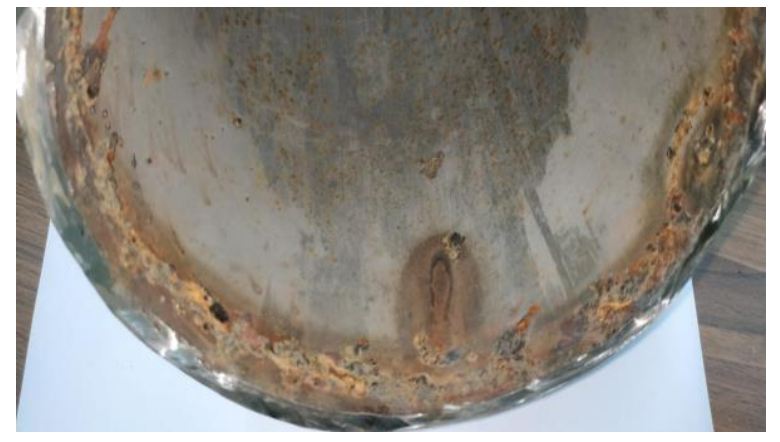

Fig. 5. Inner wall of the leaky elbow

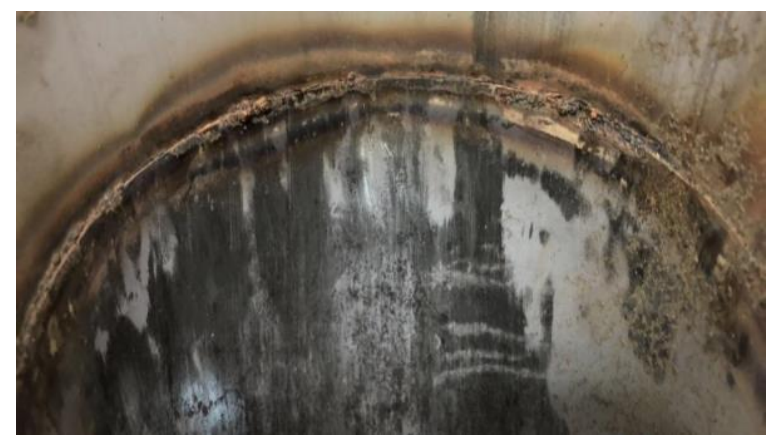

Fig. 6. Inner wall of the leak-proof elbow

\subsection{Chemical composition testing}

As illustrated in Table 1, The content of $\mathrm{Ni}$ in the elbow side base material is $0.99 \%$, and the Mn content is as high as 8.69 , which is a typical non-standard stainless steel with $\mathrm{Mn}$ substituted for $\mathrm{Ni}^{[5]}$. At the same time, the $\mathrm{C}$ content exceeded the standard, and the $\mathrm{Cr}$ content was slightly lower, which did not meet the standard requirements of GB/T 1220-2007 Stainless Steel. The composition of the straight side base metal complies with the standard requirements. The $\mathrm{C}$ content in the weld zone exceeded the standard, and the $\mathrm{Ni}$ and $\mathrm{Mn}$ contents were between the corresponding element contents of the base metal on both sides.

Table 1. Chemical composition of Welded joint.

\begin{tabular}{|c|c|c|c|c|}
\hline $\begin{array}{c}\text { Element } \\
\text { content } / \%\end{array}$ & $\begin{array}{c}\text { Elbow } \\
\text { side }\end{array}$ & $\begin{array}{c}\text { Weld } \\
\text { zone }\end{array}$ & $\begin{array}{c}\text { Straight } \\
\text { side }\end{array}$ & $\begin{array}{c}\text { standard } \\
\text { for 304 }\end{array}$ \\
\hline $\mathrm{C}$ & 0.11 & 0.11 & 0.05 & 0.08 \\
\hline $\mathrm{Si}$ & 0.35 & 0.44 & 0.55 & 1 \\
\hline $\mathrm{Mn}$ & 8.69 & 3.68 & 1.3 & 2 \\
\hline $\mathrm{P}$ & 0.038 & 0.039 & 0.031 & 0.045 \\
\hline $\mathrm{S}$ & 0.002 & 0.002 & 0.002 & 0.03 \\
\hline $\mathrm{Ni}$ & 0.99 & 5.23 & 8.1 & $8 \sim 11$ \\
\hline $\mathrm{Cr}$ & 16.91 & 18.12 & 18.2 & $18 \sim 20$ \\
\hline
\end{tabular}

\subsection{Hardness measurement}

The Brinell hardness of welded joint was measured, and the result was shown in Table 2. The average hardness of the base metal on the elbow side is $272 \mathrm{HB}$, the average hardness of the base metal on the straight side is $183 \mathrm{HB}$, and the average hardness of the weld zone is 196HB. According to the standard DL / T 869-2012 "Welding Technical Regulations for Thermal Power Plants", the hardness of the base metal should not be greater than 192HB. According to the standard DL / T 752-2010 "Technical Specification for Welding Dissimilar Steels for Thermal Power Plants", the Brinell hardness value of the weld zone shall not exceed $30 \%$ of the actual average Brinell hardness of the base metal on both sides of the joint or be lower than $90 \%$ of the lower side hardness value. It can be seen that the hardness of the base metal on the elbow side does not meet the standard requirements.

Table 2. Brinell hardness of welded joint(HB)

\begin{tabular}{|c|c|c|c|}
\hline Test number & Elbow side & Weld zone & Straight side \\
\hline 1 & 282 & 199 & 180 \\
\hline 2 & 266 & 202 & 184 \\
\hline 3 & 269 & 186 & 185 \\
\hline average & 272 & 196 & 183 \\
\hline standard & $\leqslant 192$ & $165 \sim 296$ & $\leqslant 192$ \\
\hline
\end{tabular}

\subsection{Micro analysis}

The welded joint was sampled and polished, and its section was observed. It was found that the weld bead was wide and shallow, and it should be a repair weld. The crack is located in the heat affected zone on the elbow side and extends to the base metal, as seen in 
Fig.7. The weld zone is a thick columnar dendritic structure, which indicates that the welding line energy is too large ${ }^{[6]}$. The heat-affected zone is the recrystallized refined austenite structure, and the parent material zone on the elbow side is the deformed austenite structure, which is consistent with the result of the larger hardness test value, as shown in Fig.8. Observing the crack further, it shows the cracking direction along the crystal, with obvious hot crack characteristics ${ }^{[7]}$, as shown in Fig.9.

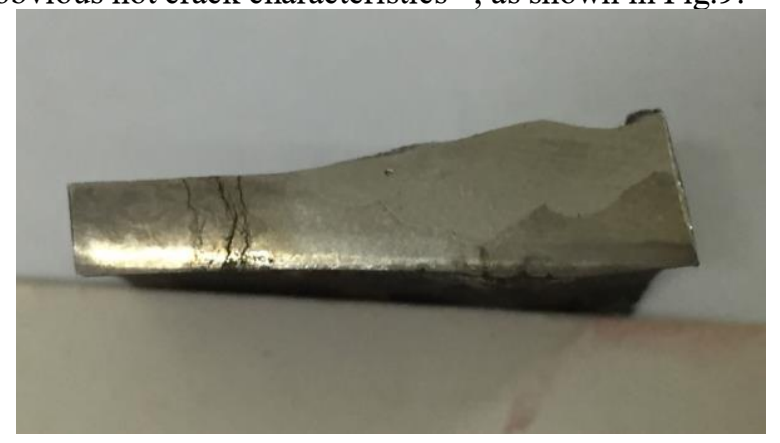

Fig. 7. Cross-section morphology of welded joints

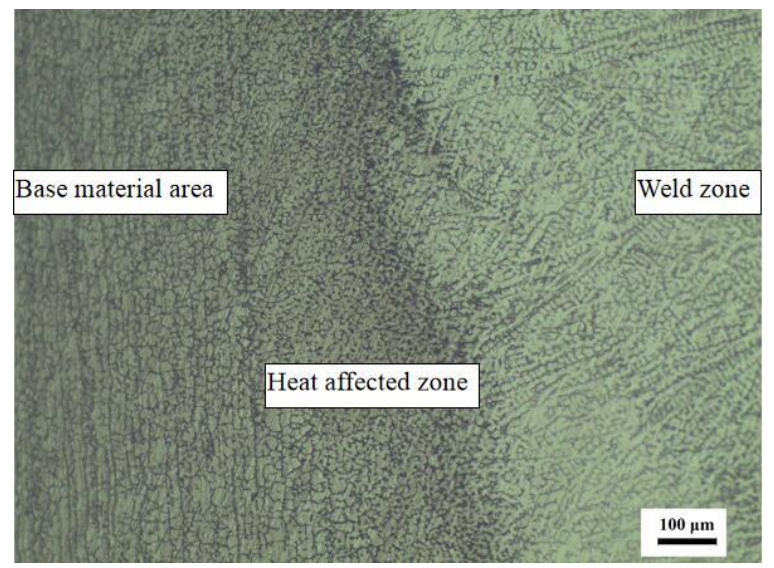

Fig. 8. Microstructure of fusion zone of welded joint

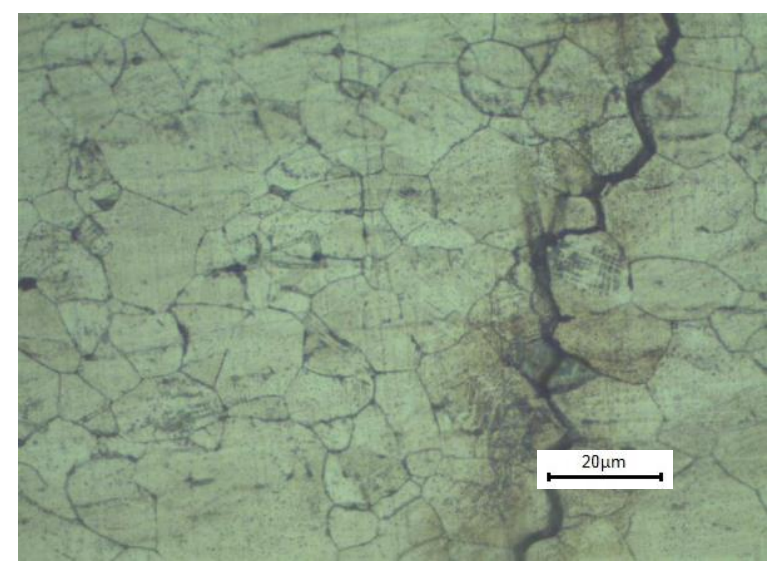

Fig. 9. Crack along crystal

\subsection{SEM and EDX analysis}

Scanning electron microscope observation of crack fracture samples indicated that the morphology showed significant characteristics of intergranular fracture ${ }^{[8]}$, as displayed in Fig.10. The fracture energy spectrum analysis results are shown in Table 3. It can be seen that $\mathrm{P}$ and $\mathrm{S}$ elements are common in the fracture.

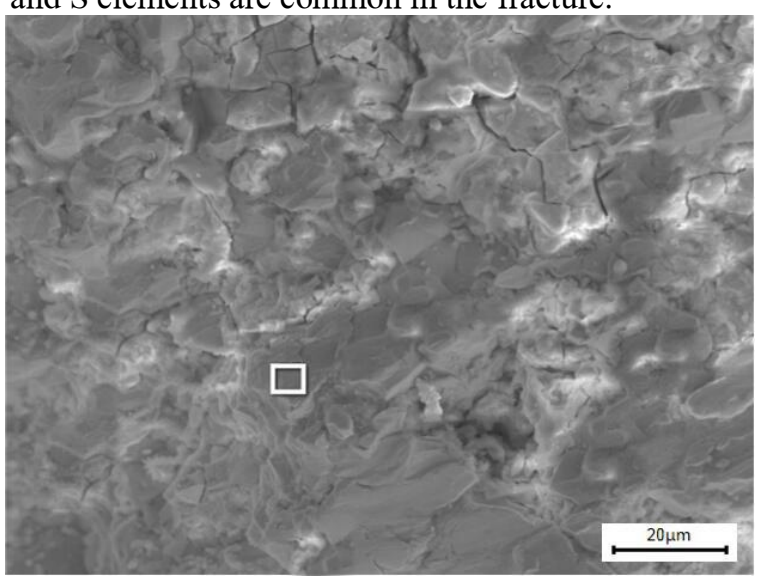

Fig. 10. Crack fracture morphology

Table 3. The results of fracture energy spectrum analysis

\begin{tabular}{|c|c|c|}
\hline element & Wt.\% & At.\% \\
\hline $\mathrm{Si}$ & 1.11 & 0.82 \\
\hline $\mathrm{Cr}$ & 20.95 & 8.38 \\
\hline $\mathrm{Fe}$ & 18.63 & 6.94 \\
\hline $\mathrm{P}$ & 0.71 & 0.48 \\
\hline $\mathrm{Al}$ & 0.78 & 0.60 \\
\hline $\mathrm{K}$ & 1.14 & 0.60 \\
\hline $\mathrm{Ca}$ & 1.12 & 0.58 \\
\hline $\mathrm{Cl}$ & 0.48 & 0.28 \\
\hline $\mathrm{Na}$ & 0.74 & 0.67 \\
\hline $\mathrm{S}$ & 0.45 & 0.29 \\
\hline
\end{tabular}

\subsection{Cause analysis}

\subsubsection{Pipe elbow material and manufacturing process are unqualified}

The design material of the pipeline is 304 austenitic stainless steel, and the actual material of the leaking pipe elbow is non-standard stainless steel with $\mathrm{Mn}$ instead of $\mathrm{Ni}$, which is unqualified. The use of non-standard stainless steel causes the pipeline to actually form a dissimilar steel weld, which is prone to produce extremely complex welding fusion zones with chemical compositions and metallurgical structures, causing premature failure of the welded joint. On the other hand, the hardness of this elbow exceeds the standard, and the metallurgical structure is deformed austenite, which means that it is not heat treated after forming and does not meet the standards of GB / T 14976-2012 "Stainless steel seamless steel tubes for fluid transport" Requirements for delivery after heat treatment and pickling. The manufacturing process is not qualified, 
resulting in greater stress in the internal structure of the elbow.

\subsection{Large welding residual stress caused by poor welding process}

Austenitic stainless steel has a large linear expansion coefficient, poor thermal conductivity, large welding stress and deformation, which is prone to cause thermal cracking. Therefore, the welding process usually requires the use of argon arc welding, using small wire energy for welding. It can be known from the coarse columnar crystals of weld metallographic structure that the line energy during welding of the pipe is too large, which will cause large welding residual stress.

\subsubsection{Grain boundary weakening in HAZ caused by welding heat}

It is shown from Scanning electron microscopy and energy spectrum analysis of the fracture that harmful elements such as $\mathrm{S}$ and $\mathrm{P}$ are generally present in the fracture. Due to the high temperature caused by the large welding line energy, S, P and other impurity elements will promote the segregation of austenitic stainless steel, and form low-melting eutectics between grains. Under the influence of welding heat, the low-melting phase on the austenite grain boundary in the heat-affected zone is re-melted to form a low-melting eutectic liquid film, which is cracked by shrinkage tensile stress in the subsequent cooling process, forming a crystal along crack.

\subsubsection{Poor corrosion resistance}

The Mn and Ni content in the weld zone is between the base materials on both sides, and the metallurgical structure is coarse columnar crystals, which is very different from the base material, resulting in different electrochemical potentials from the base material, formed a large number of corrosive microbatteries. Therefore, the corrosion rate in the water environment is faster than the base material. In addition, it can be seen from the comparison of the inner wall of the same type of non-leakage elbow that the weld seam is not beveled, and the inner wall has a large gap, which results in a large number of gaps in the weld zone of the inner wall of the elbow, forming crevice corrosion, which further exacerbates the corrosion.

\subsubsection{Comprehensive analysis}

In summary, the material and manufacturing process of the pipe elbow are unqualified, and the welding process is poor, resulting in excessive internal stress and welding stress. The strength of the low melting point eutectic phase on the austenite grain boundary in the heat affected zone of the elbow base metal during the welding thermal cycle was exceeded, causing thermal cracking. Corrosion in the weld zone of the inner wall of the elbow pipe exacerbated the crack propagation, which eventually led to the leakage of the external cold water pipeline.

\section{Conclusion}

1) The crack properties should be thermal cracks caused by severely unqualified material composition and performance of the elbow and improper high current welding process. At the same time, the problem of intergranular corrosion cracking may occur during longterm operation.

2) The operation and maintenance department should replace the leaking elbow, and carry out the elbow material inspection immediately. They also should check the elbow of non-standard material thoroughly, and immediately deal with the unqualified material. The newly replaced elbow should be strengthened the quality inspection, and the material and hardness should be qualified before using.

\section{Acknowledgments}

This work was supported by the Science and Technology Foundation of State Grid Corporation of China (Contract No.SGZJ0000KXJS1800302): Research on metallic material Selection, Manufacturing, Installation Process for Power Transmission and Transformation Equipment and Nondestructive Detection Method for Components.

\section{References}

1. Y.T.Wang, Y.C.Zhang, Q.Y.Zhou, Z.Q.Li, Y.L.Jiang, Y.Tang, J.L.Wu, C.Gao, J.Z.Tu, C.Shen, Power System Technology 41, 1(2017).

2. X.J.Shi, W.Mu, J.H, B.Fang, S.Gao, L.Wu, W.Q.Liu, Electric Power 50, 12(2017).

3. Z.P.Mao,J.L.Wu, H.Li, Hunan Electric Power 39,1 (2019).

4. M.L.Wang,H.Y.Ding, H.Y.Ding, G.Chen, H.H.Yan, Electromechanical Information 35,6 (2019).

5. W.Jiang, K.Y.Zhao, J.Su, Q.L.Yong, Heat Treatment of Metals 44, 10(2019).

6. W.Dai, T.Q.Luo, F.Wang, L.Zhang, M.Xiang, Heat Treatment of Metals 43, 5(2018).

7. D.H.Man, L.F.Wang, Hot Working Technology 41,11(2012)

8. X.S.Wang, Heat Treatment of Metals 27, 9(2002). 